Clustering university teaching staff through UTAUT: Implications for the acceptance of a new learning management system

Peer-reviewed author version

Garone, Anja; Pynoo, Bram; Tondeur, Jo; Cocquyt, Celine; Vanslambrouck, Silke;

Bruggeman, Bram \& STRUYVEN, Katrien (2019) Clustering university teaching staff through UTAUT: Implications for the acceptance of a new learning management system. In: BRITISH JOURNAL OF EDUCATIONAL TECHNOLOGY, 50(5), p. 2466-2483.

DOI: 10.1111/bjet.12867

Handle: http://hdl.handle.net/1942/29202 


\title{
Clustering university teaching staff through UTAUT: Implications for the acceptance of a new learning management system
}

Anja Garone*, Bram Pynoo, Jo Tondeur, Celine Cocquyt, Silke Vanslambrouck, Bram Bruggeman, Katrien Struyven.

Anja Garone is a PhD candidate at the Vrije Universiteit Brussel (VUB). Her research interests are in professional development in higher education in the context of blended learning.

Dr. Bram Pynoo is a researcher and pedagogical collaborator at the teacher training department of the Vrije Universiteit Brussel. His research interests concern blended learning, technology acceptance and community service learning.

Dr. Jo Tondeur is a Professor at Vrije Universiteit Brussel and he is also affiliated as guest professor at Ghent University, Belgium. His research is situated within the field of educational innovations.

Most of his research focuses on the integrated use of ICT in pre-service teacher training and compulsory education.

Dr. Céline Cocquyt obtained her PhD in Educational Sciences at the Vrije Universiteit Brussel (VUB) and is currently coordinating a project on teacher professional development for online and blended learning.

Dr. Silke Vanslambrouck obtained her PhD in Educational Sciences at the Vrije Universiteit Brussel (VUB) and is currently a collaborator for educational development at the department of quality assurance and innovation and pedagogical collaborator at the department of educational sciences. Her research interests concern blended learning, adult education, motivation and self-regulation.

Bram Bruggeman is a PhD candidate at the Vrije Universiteit Brussel (VUB). His research interests are in professional development in higher education in the context of technology enhanced learning. Dr. Katrien Struyven is an associate professor at Hasselt University (UHasselt), School of Educational Studies and Vrije Universiteit Brussel (VUB), Educational Sciences Department. Her research focuses on instructional methods (differentiated instruction methods, blended learning, PAL, studentactivating teaching methods, case-based learning, PBL) and assessment (portfolio, peer assessment, feedback).

*Address for correspondence: Anja Garone, Department of Educational Sciences, Vrije Universiteit Brussel, Pleinlaan 2 - 1050 Brussels, Belgium. Email: anja.garone@vub.be

\begin{abstract}
The unified theory of acceptance and use of technology (UTAUT) is a survey instrument used to determine technology usage intention and behaviour. UTAUT consists of four predictor variables, performance expectance, effort expectancy, social influence and facilitating conditions. This study investigates the technology acceptance profiles of university teaching staff, by using the UTAUT predictor variables as clustering variables, in the context of the implementation of a new learning management system (LMS). While students are mostly the focus of research on technology acceptance in higher education, university teaching staff are predominantly overlooked. Using a modified UTAUT questionnaire, 244 university teaching staff from a Belgian university took part in a survey focusing on their acceptance and use of the new LMS. Most studies on LMS acceptance in higher education are variable centred, whereas this research takes a person-centred approach. This approach will shed new light on how UTAUT can provide information which can be used to interpret the professional development needs during an institution-wide educational technology implementation. A cluster analysis with the predictor variables of UTAUT as input variables resulted in three distinct groups: a high, moderate and a low scoring cluster. These differences between the clusters were also reflected in the acceptance of the LMS. The results of this study will therefore facilitate decision-making and guidelines for the design of institution-wide professional development initiatives that are targeted towards the needs of specific groups of university teaching staff.
\end{abstract}

Key words: UTAUT, Cluster Analysis, University teaching staff, Learning management system 


\section{Practitioner notes:}

What is already known about this topic:

- Most research has focused on university students, or on general barriers to technology acceptance.

- The four core predictors of UTAUT are reliable determinants of intention and attitude, which in turn are direct determinants of use.

- An alternative to measuring actual use, self-reported intensity of use, has been found to be a direct determinant of actual use.

- Previous cluster analyses in connection with technology acceptance have shown that there are meaningful differences between groups of users in the way they accept and use a technology.

- Clustering gives additional information about technology users that may facilitate follow-up research or support initiatives designed to suit the needs of the groups.

What this paper adds:

- A three-solution cluster analysis reveals three distinct groups of technology acceptance in university teaching staff: High, moderate and low.

- High users are most likely to innovate.

- Moderate and low users most likely need additional support as well as increased social influence from policy and decision makers.

Implications for practice and/or policy:

- $\quad$ The professional development support needs of each group can be more easily addressed and targeted separately to suit their specific needs.

- This is an opportunity for policy and decision -makers to revise and optimise policies on LMS use as well as on the supportive initiatives needed to facilitate better and more effective use of the LMS.

- Innovating will require additional support. While the high usage group is clearly more inclined to use the system more innovatively, the two other groups will require additional resources and social pressure to influence their intentions regarding innovating. 


\section{Introduction}

Universities today are joining the technology implementation race. While technology is here to stay and access to it has increased, this does not automatically lead to an effective use of technology in educational settings (Park, Lee, \& Cheong, 2008; Tondeur, van Braak, Siddiq, \& Scherer, 2016). Related to effective use is successful implementation of educational technologies. Measuring success, however, depends largely on the context, the variables examined, and most importantly, the original objective of the implementation (DeLone \& McLean, 2003). Acceptance of a technology by its intended users is key to implementing educational technologies, which can be scrutinised through (behavioural) intentions to use or actual use of the technology (DeLone \& McLean, 2003; Venkatesh, Morris, Davis \& Davis, 2003). The Unified Theory of Acceptance and Use of Technology (UTAUT) is a widely acknowledged instrument for measuring user acceptance, operationalised as behavioural intention and/ or actual or self-reported use (Venkatesh et al., 2003); or in this case of academic staff's intentions toward using new technological applications in their educational practice. UTAUT predicts user acceptance and can thus be of interest to all potential implementers of a new technology (Pynoo et al., 2012), such as the administrators of a new learning management system (LMS) within an institute. In this respect, universities could benefit from knowing the potential determinants that influence acceptance and use of an LMS, which in turn can lead to developing tailored training geared towards the effective use of innovative educational technologies in practice.

While educational technology acceptance is well studied in university students, it has not yet been studied extensively from the point of view of university teaching staff as users (Kocaleva, Stojanovic, \& Zdravev, 2014; Vanslambrouck, Zhu, Lombaerts, Philipsen, Tondeur, 2018; Williams, Rana, \& Dwivedi, 2015). The present study takes place in a Flemish university in Belgium, where a new LMS (Canvas LMS) has replaced a previous system. The system was made available to teaching staff from May 2018, and to the students as of September 2018, for the academic year 2018-2019. The aim of the present study is to examine how university teaching staff experience the early implementation phase of the new LMS at their institute. We seek to describe how they accept the system, by grouping the users by their acceptance characteristics as well as behavioural intention to innovate with the new LMS.

\section{The UTAUT framework}

UTAUT emerged via the review and consolidation of eight competing and conceptually similar models that were used to predict or explain behaviour (Venkatesh et al., 2003). The combined and streamlined model features four core variables that predict behavioural intention and actual use: Performance Expectancy (PE), Effort Expectancy (EE), Social Influence (SI), and Facilitating conditions (FC). PE relates to the belief that using the technology will help the user to perform their job better, EE captures the degree of ease that the user associates with the technology, SI indicates how the users perceive that others who are important to them (peers, supervisors) believe that they should use the technology, and lastly, FC is a scale that encompasses the degree to which participants believe training, support, infrastructure, as well as the background knowledge are available to use the system optimally, and was originally defined as the belief that organisational and technical infrastructure exist to support the use of the new technology (Venkatesh et al., 2003; Pynoo et al., 2012).

Acceptance is a key concept within the UTAUT model. The definition and conceptualisation of which is best defined by Dillon and Morris (1996) as users who willingly use a "technology for the tasks it is designed to support" (Dillon \& Morris, 1996). The most common ways to operationalise acceptance is through measuring or observing actual use behaviour, self-reported use, attitude, and behavioural intention. Age, gender, experience and voluntariness of use serve as mediating variables that influence the relationship between the predictor variables, behavioural intention, and use. However, it is not always possible to measure actual use. An alternative is to measure self-reported frequency or intensity of use (IU), of which attitude has been shown to be a consistent predictor (Duyck et al, 2008; Pynoo et al., 2011b). Other predictors that are sometimes used in connection with UTAUT scales, such as attitude and anxiety can indicate a connection between acceptance and prior experience (Kidd, Davis \& Larke, 2016). Attitude, along with anxiety, have been excluded from the 
original UTAUT model because they were found not to be direct determinants of intention (Venkatesh et al., 2003).

The Diffusion of Innovations Theory (Rogers, 2003) - one of the eight models underlying UTAUT discerns five groups of (potential) users of an innovation with respect to the speed of adoption of the innovation: Innovators, early adopters, early majority, late majority and laggards. This suggests that factors - other than gender and age - affect (potential) users' perceptions and acceptance of technology and may be utilised to group users. In this respect, Devolder et al. (2012), utilised the five-factor model and the technology readiness index to cluster technology users. The purpose of this study is to investigate whether PE, EE, SI and FC can be used for this purpose.

The UTAUT-model has been amended and modified in many ways to suit the study of different contexts (Williams et al., 2015). The original UTAUT model (Figure 1), along with the four key scales $(\mathrm{PE}, \mathrm{EE}, \mathrm{SI}$ and $\mathrm{FC})$, continues to be the foundation for many technology acceptance studies.

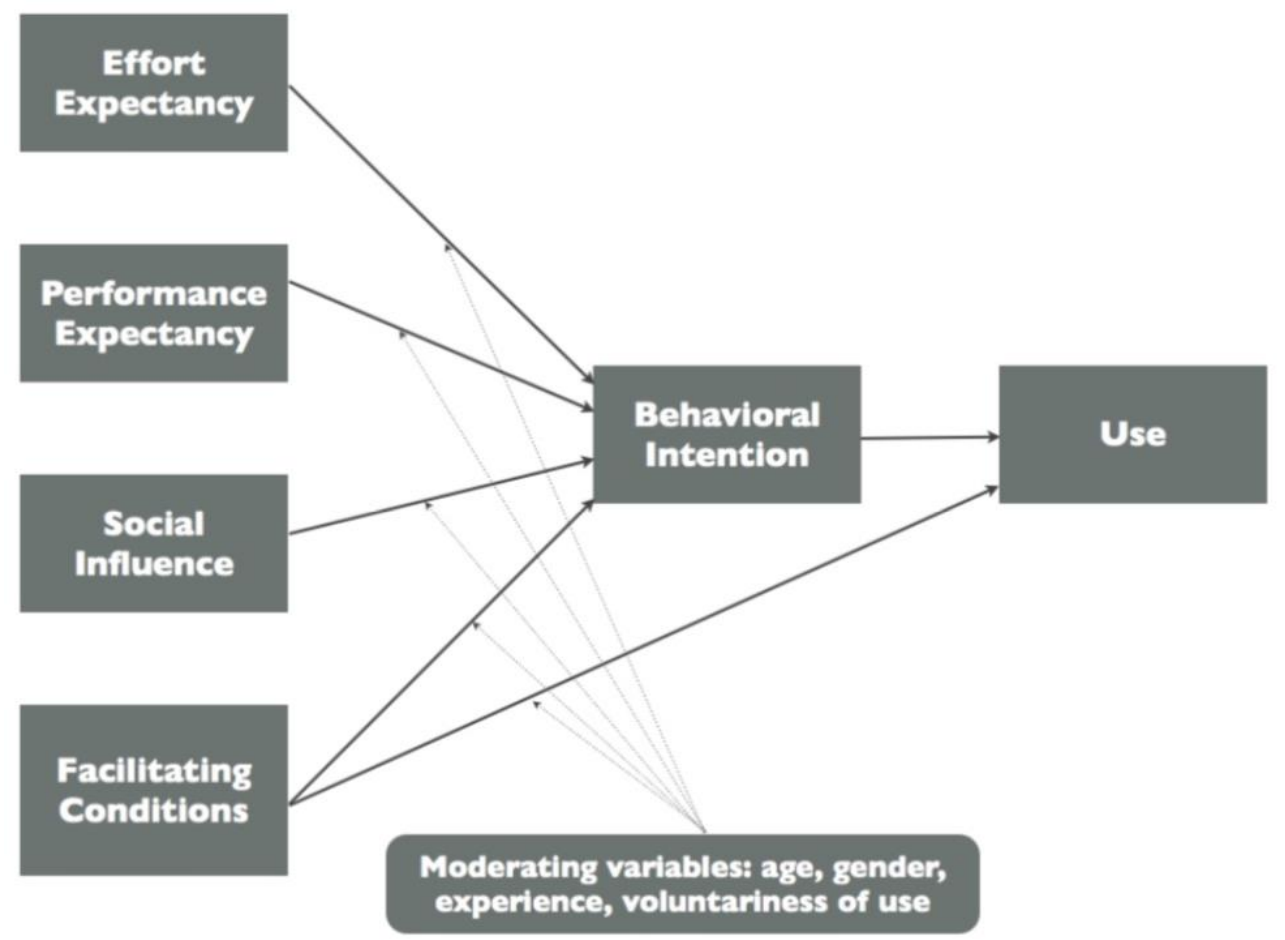

Figure 1: The UTAUT model based on the original framework by Venkatesh et al., (2003).

UTAUT-framework employed in higher education: lack of research attention to university teaching staff

While UTAUT studies involving university teaching staff are scarce, there is research using the Technology Acceptance Model (TAM) that studied university professors' LMS acceptance and use (Alsofyani, Aris, Eynon, \& Majid, 2012; Park et al., 2008). Both UTAUT and TAM continue to be used and cited in research on technology acceptance and use in higher education. The two instruments are very similar, therefore with regards to this study, UTAUT was chosen due to the main added feature, facilitating conditions, that is particularly useful in the context of researching educational technology acceptance within universities (Buchanan, Sainter, \& Saunders 2013). Facilitating conditions as a factor can provide an indication for the development of support and training initiatives specifically to maximise the uptake of the new LMS.

UTAUT, applied to the context of higher education, has been modified to suit the type of the technology being implemented, whether it is devices (Anderson, Schwager, \& Kerns, 2006), open 
access publishing (Lwoga \& Questier, 2014), social media (Gruzd, Staves, \& Wilk, 2012), online teaching tools or online LMS (Baytiyeh, 2017; Buchanan et al., 2013; Kocaleva et al., 2014; Kocaleva et al., 2015; Pynoo et al., 2011b). Concerning the use of the LMS, Blackboard, among faculty staff, Buchanan et al. (2013) studied factors affecting use in UK universities. Results showed that internet self-efficacy is positively associated with the use of Blackboard. Further significant predictors of use were structural constraints and perceived usefulness. In a similar study, Baytiyeh (2017), however, found that community influence was the strongest predictor of use.

There have been very few empirical studies investigating the adoption and use of LMSs from the point of view of the university professors. Williams et al. (2015), extensively examined the UTAUT literature to that date, documenting the domains, constructs used and reported results. Out of 174 journal articles analysed, only two reportedly included participants that were academic/faculty staff (i.e. Anderson et al., 2006; Debuse, Lawley, \& Shibl, 2008). The former authors studied faculty staff acceptance of tablet PC's and found that performance expectancy and voluntariness of use were the main predictors of use. The latter authors studied acceptance and experience with an automated feedback system present within the LMS, more importantly, how useful the academic teaching staff perceived this specific tool. The main participants were the students, while eight educators participated in the study as well. Results from the study show that there was a positive reported impact on the workload, and therefore perceived as useful by the teaching staff.

Kocaleva et al. (2015) adapted the UTAUT model to study adoption and use of an e-learning information and repository system in a Macedonian university. Apart from the four baseline constructs found in the UTAUT-model, three further determinants were added: self-confidence, anxiety and attitude towards technology use. 92 university teaching staff participated in the study. The study results mostly focus, however, on barriers for using the technology. The strongest predictors for acceptance were reportedly EE and FC. Behavioural intention, on the other hand, correlated strongly with SI and FC, indicating strong influences for use. The strongest barriers to acceptance were lack of time and investment in other commitments.

\section{Person-centred approaches to measuring acceptance or usage}

While the most common purpose for employing the UTAUT model in technology acceptance research is to identify predictors for technology use though regression analyses, some studies also use the UTAUT variables to formulate profiles through clustering study participants into groups via a cluster analysis, or cluster participants in connection with UTAUT variables (e.g., Devolder et al., 2012; Pynoo et al., 2011a). In the Pynoo et al. (2011a) study situated in secondary education, with teachers as participants, a cluster analysis was performed based on analytical data from the teaching portal, KlasCement. The purpose was to determine different user groups of the portal and to describe their usage behaviours. Next to the new users, three more groups were discerned: heavy, medium, and light users. Interestingly, the portal analytics allowed for analyses of group usage trends, revealing that, over time, light and medium users downloaded more content per login and needed to consult fewer pages, indicating an increase in portal use efficiency (Pynoo et al., 2011a). This study reveals information about the participants that explains intention and use with deeper, fine grained results. Devolder and colleagues (2012) showed through their multi-layered clustering study that different groups, accept technology in different ways. The study concludes that institutes need to implement technologies by considering the individual needs of users. By employing a personcentred approach, users can be split into sub-groups, providing an effective management solution for targeting individual groups with similar needs for support during the implementation process (Pynoo et al., 2012).

\section{Problem statement and Purpose of the current study}

While students are mostly the focus of educational technology acceptance research in higher education, professors and other university teaching staff are often overlooked, even though they are important stakeholders in the implementation of these systems. The benefits of learning management systems are promising; however, these benefits can only be attained when the systems are used efficiently. Inefficiency and a mismatch between usefulness and ease of use can 
result in dissatisfaction, and eventual rejection of the system among various stakeholders (Park et al., 2008; Tondeur et al., 2016). In the context of this study, university teaching staff, comprised of post graduate students, assistants and professors, have diverse backgrounds and find themselves with a great amount of freedom to approach and design their teaching. The pedagogical/didactical backgrounds are equally diverse, as in the context of Belgium, until recently, professors were not required to follow pedagogical training as a prerequisite to lecture at universities. While in this context, the use of the LMS was per institution-wide policy mandatory, the teaching staff nevertheless enjoy the freedom to approach the design and deliverance of their courses at their own discretion. Mapping the characteristics and needs of groups of similar users can provide vital knowledge that can guide future initiatives, such as targeted professional development sessions. This study therefore adopts a person-centred approach to understand what the challenge of technology implementation means from the point of view of the users, and aims to describe the technology acceptance and use profiles by clustering the participants based on the four core UTAUT predictor variables: Performance expectancy, effort expectancy, social influence and facilitating conditions.

\section{Method}

\section{Instrument}

The survey was part of a larger study, with the aim to investigate professionalisation needs for blended learning, in the context of a newly implemented LMS. The questionnaire employed a 7-point Likert scale across all scales (1: strongly disagree to 7: strongly agree) and incorporated the four main UTAUT scales (Venkatesh et al. 2003), as well as additional scales: attitude, anxiety, behavioural intention to innovate and self-reported intensity of use. Further demographic items such as academic positions as well as their faculty affiliation were included. Academic position categories, and a list of faculties are presented in Table 2. The items were translated from English into Dutch, with the translations cross checked and pre-tested. Participants had to agree with the informed consent in order to fill out the survey. The survey items can be found in Appendix A.

An analysis of the scales in SPSS revealed that some items needed to be deleted to improve the internal reliability of the scales. Two items of the SI scale that focused on peers and colleagues were removed, leaving four items that focused on institutional decision makers. The new scale was thus renamed "Social influence policy". Likewise, the scale FC had one item that referred to "using innovatively" rather than just "use" as the rest of the items, and therefore the item was struck from the scale leaving six items. Self-reported intensity of use was included instead of actual use (which could not be measured within the scope of this study). As a stand-alone item, it serves to further describe the behavioural characteristics of the participants. The overall scale means, number of items and reliability statistics are presented in Table 1.

Table 1: Overall mean scores and reliability statistics for the scales and items

\begin{tabular}{llrrrr} 
& $\mathrm{N}$ & $\mathrm{N}$ items & Mean & Std. Deviation & Reliability (a) \\
\hline Performance expectancy & 193 & 4 & 4.24 & 1.15 & .799 \\
Effort expectancy & 193 & 4 & 4.84 & 1.25 & .931 \\
Social influence policy & 193 & 4 & 4.79 & .96 & .775 \\
Facilitating conditions & 193 & 6 & 4.37 & 1.03 & .829 \\
Attitude & 174 & 5 & 4.51 & 1.19 & .892 \\
Anxiety & 193 & 6 & 2.35 & .99 & .808 \\
Behavioural intention to & 193 & 3 & 3.89 & 1.42 & .888 \\
innovate & & & & & \\
Self-reported intensity of use & 174 & 1 & 4.65 & 1.67 & - \\
Valid N (listwise) & 174 & & & &
\end{tabular}


The survey was sent out via email to university employees that include professors, pedagogical staff, teaching assistants, post-docs and PhD students who are involved in teaching in various ways. Out of a total of 244 respondents, 193 respondents completed the UTAUT part of the survey; 19 respondents dropped out for attitude and self-reported intensity of use, but they were withheld for this study. The incomplete scales received a "missing" when the participant completed less than $25 \%$ of the scale. No imputation techniques were used to replace the missing values, and missing data was dealt with in a list-wise deletion approach. Thus, the scales Attitude and self-reported intensity of use were computed with 174 responses. A description of the respondents' academic positions and faculty affiliations can be found in Table 2 . Participation in the survey was completely voluntary.

Table 2: Respondent positions and faculties

\begin{tabular}{ll} 
Respondents & $\mathrm{N}(\%)$ \\
\hline $\begin{array}{l}\text { Position } \\
\text { Appointed professors }\end{array}$ & $126(51.64)$ \\
$\begin{array}{l}\text { Post-graduates (doctoral and post-doctoral students) } \\
\text { Other teaching staff (practical assistants, non-academic } \\
\text { teaching staff, and "other") }\end{array}$ & $68(27.87)$ \\
& \\
Faculties & \\
Medicine and pharmacology & $40(16.33)$ \\
Social sciences and Solvay business school & $40(16.33)$ \\
Sciences and bioengineering sciences & $37(15.51)$ \\
Engineering & $35(14.29)$ \\
Arts and philosophy & $33(13.47)$ \\
Psychology and educational sciences & $32(13.06)$ \\
Physical education and physiotherapy & $13(5.31)$ \\
Law and criminology & $14(5.71)$ \\
\hline
\end{tabular}

Data analysis

A two-step cluster analysis was conducted. First, a hierarchical cluster analysis was performed to identify possible clusters (Milligan, 1980; Yim \& Ramdeen, 2015). This procedure is used to group participants who have similar scores within the same cluster. The clustering variables were the four UTAUT scales: performance expectancy, effort expectancy, social influence (policy) and facilitating conditions. The cluster analyses were based on the full sample of 193 university teaching staff who completed all the UTAUT scales. An inspection of the agglomeration schedule and scree plot, as well as the dendrogram revealed that there are four possible clusters within this sample. All the tables and figures associated with the hierarchical cluster analysis can be found in Appendix B.

As a second step, a K-means clustering procedure was conducted first with a specified number of four clusters, followed by a specification of three clusters (Table 3) (Milligan, 1980). Cluster analysis is a method that allows much interpretative freedom to the researcher (Tondeur, Hermans, van Braak, \& Valcke, 2008; Yim \& Ramdeen, 2015), allowing for multiple solutions to the analysis concerning the number of clusters. In this study a three-cluster solution analysis is presented, because in the four-cluster solution, one cluster only had nine cases. A one-way ANOVA along with post-hoc tests were computed to study the differences between the groups, as well as correlations between the scales.

\section{Results}

Results from the $k$-means clustering

The focus of this study is on the three-cluster solution resulting from the four UTAUT scales. Based on the K-means cluster analysis, $86(44.55 \%)$ respondents were classified into cluster 1, 79 $(40.93 \%)$ into cluster 2 and $28(14.50 \%)$ into cluster 3 . The differences between the clusters were statistically significant for each of the UTAUT scales: $\operatorname{PE}\left[F(2,190)=82.56, p<.001, \eta^{2}=.47\right]$; EE 
$\left[F(2,190)=211.29, p<.001, \eta^{2}=.69\right]$, Sip $\left[F(2,190)=26.18, p<.001, \eta^{2}=.22\right]$ and $F C[F(2$, $\left.190)=134.94, \mathrm{p}<.001, \eta^{2}=.59\right]$. The additional scale scores also showed significant differences between the clusters: ATT $\left[F(2,171)=59.38, p<.001, \eta^{2}=.48\right]$; ANX $[F(2,190)=20.15, p<.001$, $\left.\eta^{2}=.18\right]$; and BII $\left[F(2,190)=17.36, \mathrm{p}<.001, \eta^{2}=.15\right]$. However, post-hoc tests (Bonferroni and Tukey HSD) revealed only one non-significant difference, which was between clusters 2 and 3 in the behavioural intention to innovate scale $(M=.06(.29) p=.98)$. Table 3 presents a comparison of the mean scores of all the scales within each cluster.

Table 3: Scale means and case numbers within clustering groups and additional scale mean scores

\begin{tabular}{|c|c|c|c|}
\hline Scales & & Clusters & \\
\hline & 1 & 2 & 3 \\
\hline $\mathrm{N}$ in each cluster & 86 & 79 & 28 \\
\hline PE & $5.07(.80)$ & $3.76(.82)$ & $3.03(1.05)$ \\
\hline $\mathrm{EE}$ & $5.73(.70)$ & $4.66(.69)$ & $2.62(.76)$ \\
\hline FC & $5.21(.68)$ & $3.85(.63)$ & $3.23(.70)$ \\
\hline Sip & $5.25(.81)$ & $4.57(.86)$ & $4.02(.97)$ \\
\hline ATT* & $5.33(.81)$ & $4.07(.86)$ & $3.07(1.05)$ \\
\hline sr-IU* & $5.47(1.28)$ & $4.18(1.56)$ & $3.28(1.75)$ \\
\hline BII & $4.51(1.30)$ & $3.41(1.33)$ & $3.35(1.30)$ \\
\hline ANX & $1.94(.79)$ & $2.53(.99)$ & $3.10(.97)$ \\
\hline
\end{tabular}

* ATT and sr-IU were calculated with 174 respondents.

An examination of each cluster reveals that cluster 1 scored highest on all scales, except anxiety (indicating lowest self-reported anxiety). Cluster 2 scored moderately, and cluster 3 scored lowest on all scales except anxiety, see Figure 2.

\section{Description of the clusters}

Participants in cluster 1 showed high UTAUT scores. This group scored the highest on the EE scale meaning that they feel they can use the new LMS easily. The intensity of use score is slightly higher than the scores for social influence and facilitating conditions, which may be an indication of high self-efficacy for what concerns using the LMS. The score on behavioural intention may indicate a wish to use the system effectively, instead of a readiness to use it to innovate with their teaching. As expected, the group has the lowest score for anxiety. This cluster bears similarities with the innovators and early adopters' profiles of the diffusion of innovations theory (Rogers, 2003). Thus, we label this cluster as "the early adopters".

The second cluster, showed moderate UTAUT scores. PE and FC seem lower than the other UTAUT scales (EE and Sip). This may indicate that they don't find the system as useful (PE), but they do find it easy to use (EE), which may account for the slight rise in attitude and intensity of use, despite the slightly lower PE. The high SIp and moderate IU is an indication of using the system because they are required to do so, or since the institutional policy dictates that they are obliged to use the new system, which has replaced a previous LMS. The slightly lower FC may be an indication that this group may need to be reached out to for increased support. This cluster bears similarities with the early majority profile of the diffusion of innovations theory (Rogers, 2003). This cluster is thus labeled as "the early majority".

The third cluster scored the lowest on all the scales except for anxiety (yet higher scores indicate higher anxiety). Members of this cluster do not find the LMS easy to use (EE) nor do they find it useful (PE); and the low FC score indicates that they do not feel adequately supported to use the LMS. This is also reflected in low scores on ATT and IU. The highest score of this cluster falls under social influence, yet, as this score (4.02) is close to the neutral point of the scale, this indicates that the peers play no role in the adoption process. This cluster bears similarities with the late majority 
and laggards profiles of the diffusion of innovations theory (Rogers, 2003). This cluster is therefore labeled as "the late majority".

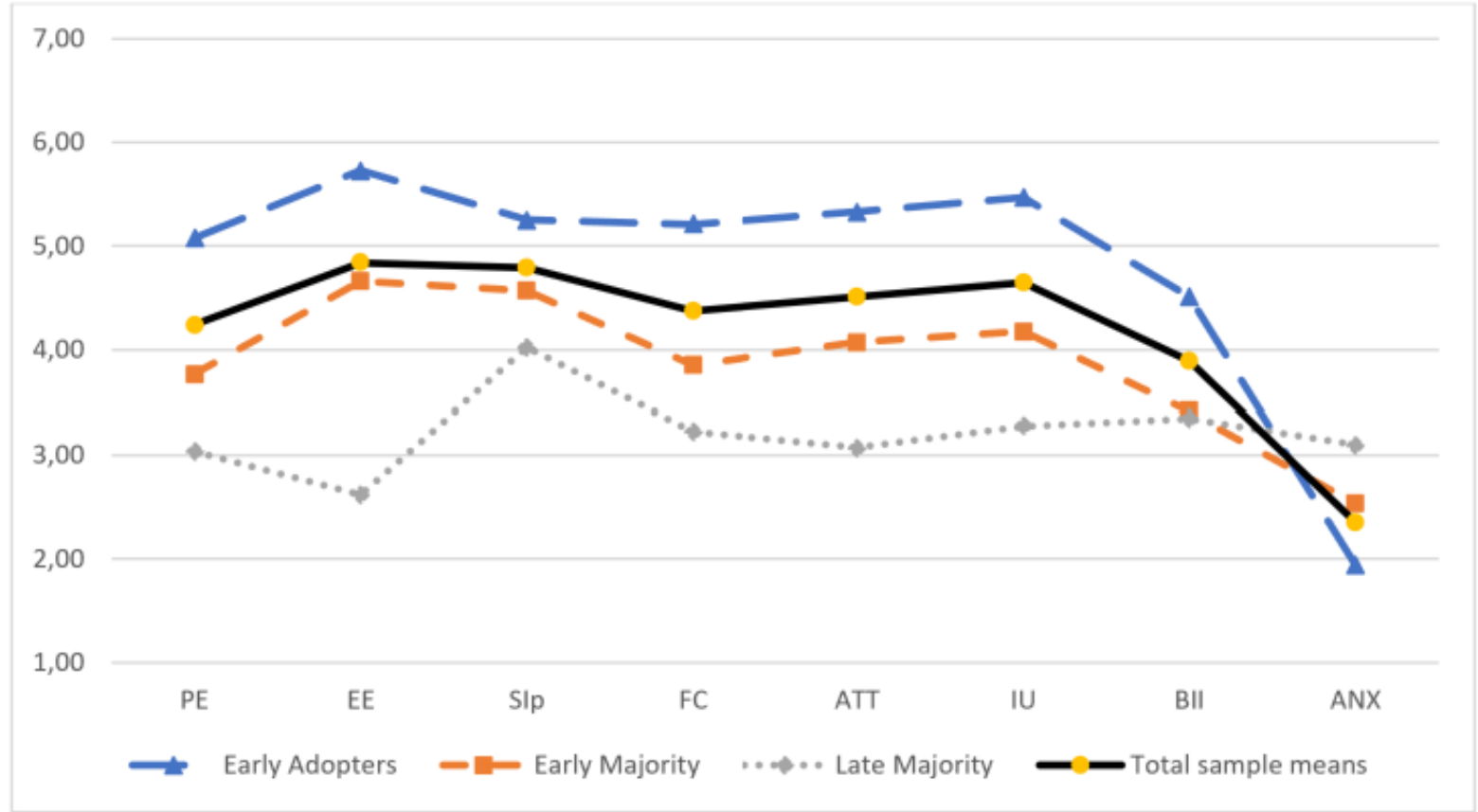

Figure 2: Mean scores of the clusters on the scales alongside the total sample means.

Linking the profiles to position and faculty affiliation of participants

The cluster groups were compared to the characteristics of the participants, which were academic position and faculty affiliation. Participants were grouped into two groups, professors and other university teaching staff (comprised of doctoral students, post docs, and all other teaching staff) There was no significant association between cluster membership and academic position, $\mathrm{X}_{2}(2)=.453, \mathrm{p}=.80$. This result indicates that the level of acceptance (High, average or low) is not determined by the participants' academic position.

A Chi-square test to investigate the association between cluster membership and faculty was not possible because of the low participant number per cluster in some faculties. Therefore, the faculties were grouped together according to their doctoral schools affiliations within the university: Human sciences (4 faculties), Natural sciences and engineering ( 2 faculties), and life sciences and medicine ( 2 faculties). No significant association was found between faculty-group affiliation and cluster membership, $x_{2}(4)=9.13, p=.06$. Figure 3 illustrates the break-down of the clusters according to faculty affiliation. This gives each faculty a "clustering profile". The faculties with the highest number of cluster 1 participants are medicine and pharmacology, arts and philosophy and psychology and educational sciences. The sciences and bio-engineering faculty has the highest number of cluster 2 participants while the engineering faculty has the highest number of participants from cluster 3. 


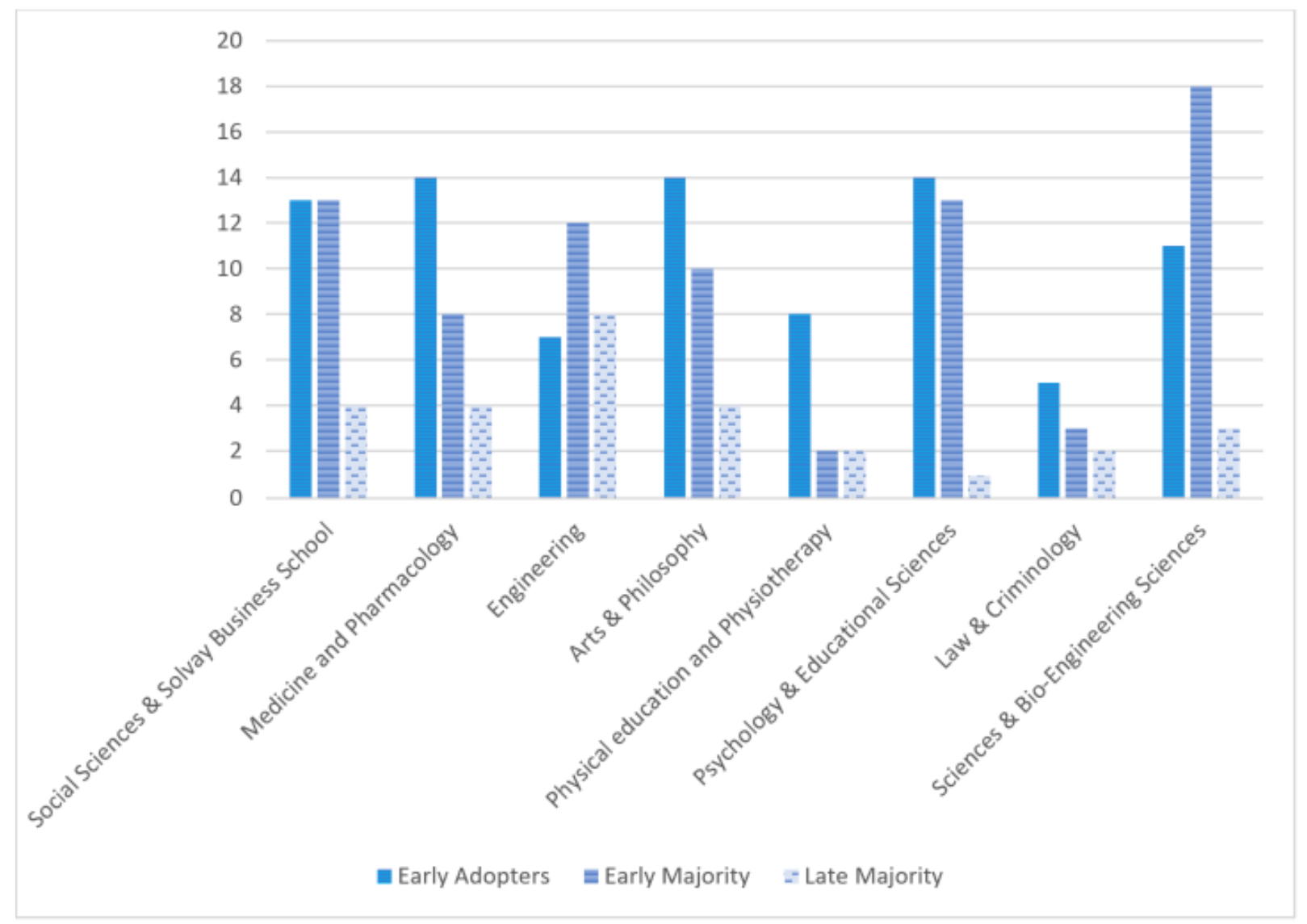

Figure 3: Clustered bar chart showing the break-down of cluster members across the faculties

\section{Scale correlations}

The correlations (Table 4) between the UTAUT scales (PE, EE, SI, FC, IU) are high, as expected (Venkatesh et al., 2003). ATT correlates highly with PE, EE, and BII. BII on the other hand correlates highest with PE. There appears to be no significant correlation between BII and ANX.

Cluster 1 correlations are significantly high between PE, EE, FC and IU (all $p<.001$ ). SIp does not correlate significantly with any of the scales. ANX correlates negatively with $E E(r=-.404, p \leq .001)$, FC $(r=-.390, p \leq .001)$ and ATT $(r=-.338, p<.001)$.

Cluster 2 correlate differently to cluster 1 . The only significant correlations for this cluster are between BII, PE $(r=.569, p<.001)$ and $\operatorname{SIp}(r=.250, p<.05)$, and between ATT, PE $(r=.699, p<.001)$ and EE $(r=.303, p<.05)$. IU correlates significantly with ATT $(r=.41, p<.001)$ and BII $(r=.313$, $\mathrm{p}<.001)$.

Cluster 3 has significantly high correlations between BII, EE $(r=.377, p<.05), P E(r=.699, p<.001)$ FC $(r=.383, p<.05)$, and ATT $(r=.571, p<.001)$. Furthermore, a significantly high correlation is evident between IU, PE $(r=.568, p<.001)$, EE $(r=.433, p<.001)$ and Sip $(r=.414, p<.05)$. 
Table 4: Correlations between scales, and correlations per cluster\$ (Pearson, sig. 2-tailed)

\begin{tabular}{|c|c|c|c|c|c|c|c|c|}
\hline & $P E$ & $E E$ & $F C$ & $A T T$ & $A N X$ & $B I I$ & SIp & $I U$ \\
\hline \multirow[t]{2}{*}{$P E$} & & $.604 * *$ & $.610^{* *}$ & $.870 * *$ & $-.288^{* *}$ & $.636 * *$ & $.378^{* *}$ & $.571^{* *}$ \\
\hline & $.326 * *$ & & & & & & & \\
\hline \multirow[t]{3}{*}{$E E$} & -.028 & & $.668^{* *}$ & $.729 * *$ & $-.484 * *$ & $.285^{* *}$ & $.340 * *$ & $.550 * *$ \\
\hline & .368 & & & & & & & \\
\hline & $.401 * *$ & $.442 * *$ & & & & & & \\
\hline \multirow[t]{3}{*}{$F C$} & -.202 & -.093 & & $.646 * *$ & $-.416 * *$ & $.353^{* *}$ & $.437 * *$ & $.492 * *$ \\
\hline & $.478^{*}$ & $.538^{* *}$ & & & & & & \\
\hline & $.757 * *$ & $.576 * *$ & $.562 * *$ & & & & & \\
\hline \multirow[t]{3}{*}{$A T T$} & $.699 * *$ & $.303 *$ & -.193 & & $-.386 * *$ & $.590 * *$ & $.411 * *$ & $.613 * *$ \\
\hline & $.851 * *$ & .357 & .334 & & & & & \\
\hline & -.19 & $-.404 * *$ & $-.390 * *$ & $-.338 * *$ & & & & \\
\hline \multirow[t]{3}{*}{$A N X$} & .118 & -.201 & .028 & .031 & & -.041 & $-.154 *$ & $-.430 * *$ \\
\hline & .045 & -.259 & -.182 & -.086 & & & & \\
\hline & $.504 * *$ & .044 & .073 & $.425 * *$ & .132 & & & \\
\hline \multirow[t]{3}{*}{$B I I$} & $.569 * *$ & -.059 & .028 & $.545^{* *}$ & .128 & & $.298 * *$ & $.352 * *$ \\
\hline & $.699 * *$ & $.377 *$ & $.383 *$ & $.571 * *$ & .134 & & & \\
\hline & .051 & .008 & .135 & .126 & .012 & .13 & & \\
\hline \multirow[t]{3}{*}{ SIp } & .122 & -.159 & .121 & .086 & .113 & $.250 *$ & & $.363^{* *}$ \\
\hline & .14 & -.002 & .252 & .252 & -.031 & -.019 & & \\
\hline & $.409 * *$ & $.449 * *$ & $.394 * *$ & $.490 * *$ & $-.406 * *$ & .042 & .065 & \\
\hline \multirow[t]{2}{*}{$I U$} & .232 & .174 & -.061 & $.410 * *$ & -.185 & $.313^{*} *$ & .165 & \\
\hline & $.568^{* *}$ & $.433^{*}$ & .338 & .389 & -.272 & .322 & $.414^{*}$ & \\
\hline
\end{tabular}

$\$$ Coefficients in grey-shaded area refer to the scale correlations per cluster. Cluster 1 in bold, cluster 2 in roman, cluster 3 in italics. * $p<.05 ; * * p<.001$

\section{Discussion}

The UTAUT is an empirically validated unification of the main technology acceptance models, and hence is considered to be a reliable and useful instrument (Venkatesh et al., 2003). While many studies using UTAUT set in higher education have been published, not many explore university teaching staff as users. To the best of our knowledge, no study has made use of the UTAUT variables as clustering variables with university teaching staff in the context of the implementation of a LMS. Three clusters were identified following a cluster analysis with the UTAUT scales as input variables, and results identified three LMS acceptance groups which align with Roger's diffusion of innovation theory: High - "the early adopters", average - "the early majority", and low - "the late majority".

Using and innovating: Cluster correlation significance

Correlations between the scales confirm the findings by Venkatesh et al. (2003) that usefulness and ease of use are highly correlated, and the same for attitude and intensity of use (Duyck et al, 2008; Pynoo et al., 2011b). However, it was found that the intention to innovate is also most highly affected by how useful the users find the LMS.

Correlations per cluster also reveal some interesting insights. Results showed that the early adopters are mostly affected by facilitating conditions, which may determine their use. However, it is observed that the willingness to accept and use this technology will be affected by anxiety.

The early majority might be more likely to start innovating with increased social influence, such as pressure from their superiors.

The late majority in their turn, might start using the system more with increased social influences (SI). With additional facilitating conditions (FC), such as support and ease of use (EE) of the system, the late majority might be willing to start innovating as well. These results support the findings from previous literature and give a clear indication of how these three groups may be approached 
differently regarding supportive initiatives, and what their priorities are for using of the system (Baytiyeh, 2017; Buchanan, et al., 2013; Kocaleva et al., 2015). What we know from literature are the typical factors of LMS acceptance for university teaching staff, which this study confirms. What we know now are the factors that may increase the intention to innovate in teaching using an LMS. Thus, training programmes should therefore not only focus on the usefulness (PE) of the LMS but also on efficient use, as these correlate significantly with intensity of use, and more importantly, with behavioural intention to innovate in the case of the late majority. While this should apply to all users, the late majority seems to particularly need a focus on EE.

\section{Implications for further research and practice}

We recommend that further research takes a closer look into the differences between the clusters with respect to the other factors, such as faculty affiliation, academic position and different types of experience (teaching experience, pedagogical background knowledge, experience using educational technology).

Ideally, the information gained from these clusters allows for the design of a concrete support plan for the use of educational technology that can be applied throughout the university. Professional development support initiatives can be a costly endeavour. Effective organisation of such initiatives thus requires decisions informed by evidence. While the questions concerning the "what" in technology acceptance are well known, such as barriers, challenges, and facilitation, this study seeks to understand the "who". A one-size-fits-all blanket solution does not consider the individual needs of the persons involved in the initiative (Devolder et al., 2012). Thus, a person-centred approach can pave the way to developing initiatives tailored to the needs and preferences of clusters of university teaching staff.

Furthermore, we see that these groups behave very differently to the different variables regarding use and innovation. The results clearly indicate, however, that the role of support (facilitating conditions) and pressure from their superiors (social influence policy) is correlated with the use, and even willingness to innovate using the new LMS. These results therefore present an opportunity for policy and decision -makers to revise key policies and vision concerning the use of the LMS, and to optimise communication for supportive initiatives throughout the university.

\section{Limitations}

Actual use was not measured in this survey, instead, we relied on the self-reported intensity of use. Nevertheless, previous research has shown that self-reported intensity of use is a direct determinant of actual use (Duyck et al, 2008; Pynoo et al., 2011b). Furthermore, as this study uses data from a larger project, gender and age were not controlled as these variables were not available in the original data set. Actual use measurement, along with gender and age will be considered in a followup study.

\section{Validation and recommendation for future research}

To validate the clusters there are several strategies. Additional data gathered from separate but contextually similar institutes can provide an opportunity to compare clustering results from two separate data sets. Additionally, qualitative interviews with participants can be conducted to confirm the link between the respondents and their cluster membership (Vanslambrouck et al., 2018). Additionally, latent profile or class analyses along with adding variables to the clustering can aid in revealing additional groups and attributes. All these steps are planned for a future study along with the possibility to explore and confirm the possible 4-cluster solution within a larger sample which was not included in this study because of the very low group numbers.

\section{Conclusion}

The aim of this study was to describe technology acceptance profiles in university teaching staff, a vital group of educational technology users whose acceptance and use of technology can partially determine the outcomes of technology implementation at universities. A person-centred approach was employed, and a subsequent cluster analysis revealed a three-cluster solution. The emerging profiles are consistent with Rogers' diffusion of innovations theory, showing a group that scored high on the UTAUT scales, corresponding to early adopters, a second group with moderate scores 
corresponding to the early majority and a third group with overall lowest scores corresponding to the late majority. Of the three groups, the early adopters are most willing to innovate, while the other two will likely require additional support to start using or innovating. The role social influence and ease of use on the early majority and late majority seems to play a significant role. These results present an excellent opportunity for the optimisation of key policies concerning the use and support offered throughout the university.

\section{Acknowledgements}

The authors wish to thank the entire team of the university's teaching and innovation department for their valuable help and input that went into constructing and sending out the survey, which has made this study possible.

\section{Statements on open data, ethics and conflict of interest}

To ensure confidentiality, participants' personal identifiers were removed prior to processing the data. The library of the VUB will provide free and open access to the SPSS file of the study as soon as the manuscript is published online. There is no conflict of interest. 


\section{References}

Alsofyani, M. M., Aris, B. B., Eynon, R., \& Majid, N. A. (2012). A preliminary evaluation of short blended online training workshop for TPACK development using technology acceptance model. Turkish Online Journal of Educational Technology-TOJET, 11(3), 20-32.

Anderson, J. E., Schwager, P. H., \& Kerns, R. L. (2006). The drivers for acceptance of tablet PCs by faculty in a college of business. Journal of Information Systems Education, 17(4), 429.

Baytiyeh, H. (2017). Perceptions of Professors and Students towards Moodle: A Case Study. In Exploring the New Era of Technology-Infused Education (pp. 206-229). IGI Global.

Buchanan, T., Sainter, P., \& Saunders, G. (2013). Factors affecting faculty use of learning technologies: Implications for models of technology adoption. Journal of Computing in Higher education, 25(1), 1-11.

Debuse, J. C., Lawley, M., \& Shibl, R. (2008). Educators' perceptions of automated feedback systems. Australasian Journal of Educational Technology, 24(4).

Delone, W. H., \& McLean, E. R. (2003). The DeLone and McLean model of information systems success: a ten-year update. Journal of management information systems, 19(4), 9-30.

Devolder, P., Pynoo, B., Sijnave, B., Voet, T., \& Duyck, P. (2012). Framework for user acceptance: Clustering for fine-grained results. Information \& Management, 49(5), 233-239.

Dillon, A., \& Morris, M. G. (1996). User acceptance of new information technology - theories and models. In M. Williams (Ed.), Annual Review of Information Science and Technology (Vol. 31, pp. 332). Medford NJ: Information Today.

Duyck, P., Pynoo, B., Devolder, P., Voet, T., Adang, L., \& Vercruysse, J. (2008). Do hospital physicians really want to go digital? --Acceptance of a picture archiving and communication system in a university hospital. RoFo: Fortschritte auf dem Gebiete der Rontgenstrahlen und der Nuklearmedizin, 180(7), 631-638.

Gruzd, A., Staves, K., \& Wilk, A. (2012). Connected scholars: Examining the role of social media in research practices of faculty using the UTAUT model. Computers in Human Behavior, 28(6), 23402350.

Kidd, T., Davis, T., \& Larke, P. (2016). Experience, adoption, and technology: Exploring the phenomenological experiences of faculty involved in online teaching at One School of Public Health. International Journal on E-Learning, 15(1), 71-99.

Kocaleva, M., Stojanovic, I., \& Zdravev, Z. (2014). Research on UTAUT Application in Higher Education Institutions. In: ITRO 2014, 27 June 2014, Zrenjanin, Serbia.

Kocaleva, M., Stojanovic, I., \& Zdravev, Z. (2015). Model of e-learning acceptance and use for teaching staff in Higher Education Institutions. International Journal of Modern Education and Computer Science (IJMECS), 7(4), 23-31.

Lwoga, E. T., \& Questier, F. (2014). Faculty adoption and usage behaviour of open access scholarly communication in health science universities. New Library World, 115(3/4), 5- 5.

Milligan, G. W. (1980). An examination of the effect of six types of error perturbation on fifteen clustering algorithms. Psychometrika, 45(3), 325-342. 
Park, N., Lee, K. M., \& Cheong, P. H. (2008). University instructors' acceptance of electronic courseware: An application of the technology acceptance model. Journal of Computer-Mediated Communication, 13(1), 163-186.

Pynoo, B., Devolder, P., Tondeur, J., Van Braak, J., Duyck, W., \& Duyck, P. (2011a). Predicting secondary school teachers' acceptance and use of a digital learning environment: A cross-sectional study. Computers in Human Behavior, 27(1), 568-575.

Pynoo, B., Devolder, P., Tondeur, J., Van Braak, J., Duyck, W., \& Duyck, P. (2011b) University Students' Acceptance of A Web-Based Course Management System. In: Teo T. (eds) Technology Acceptance in Education. SensePublishers

Pynoo, B., Tondeur, J., Van Braak, J., Duyck, W., Sijnave, B., \& Duyck, P. (2012). Teachers' acceptance and use of an educational portal. Computers \& Education, 58(4), 1308-1317.

Rogers, E. (2003). Diffusion of Innovations, 5th Edition. New York, NY: Simon and Schuster, ISBN 978-0-7432-5823-4.

Tondeur, J., Hermans, R., van Braak, J., \& Valcke, M. (2008). Exploring the link between teachers' educational belief profiles and different types of computer use in the classroom. Computers in human Behavior, 24(6), 2541-2553.

Tondeur, J., van Braak, J., Siddiq, F., \& Scherer, R. (2016). Time for a new approach to prepare future teachers for educational technology use: Its meaning and measurement. Computers \& Education, 94, 134-150.

Vanslambrouck, S., Zhu, C., Lombaerts, K., Philipsen, B., \& Tondeur, J. (2018). Students' motivation and subjective task value of participating in online and blended learning environments. The Internet and Higher Education, 36, 33-40.

Venkatesh, V., Morris, M. G., Davis, G. B., \& Davis, F. D. (2003). User acceptance of information technology: Toward a unified view. MIS quarterly, 425-478.

Williams, M. D., Rana, N. P., \& Dwivedi, Y. K. (2015). The unified theory of acceptance and use of technology (UTAUT): a literature review. Journal of Enterprise Information Management, 28(3), 443488.

Yim, O., \& Ramdeen, K. T. (2015). Hierarchical cluster analysis: comparison of three linkage measures and application to psychological data. The quantitative methods for psychology, 11(1), 821. 


\begin{tabular}{|c|c|}
\hline Codes & Item \\
\hline Faculty & What is your (main) faculty affiliation? \\
\hline Position & What is your academic position? \\
\hline \multicolumn{2}{|c|}{ Performance } \\
\hline \multicolumn{2}{|c|}{ Expectancy } \\
\hline PE1 & I would find Canvas useful within my teaching assignments. \\
\hline PE2 & $\begin{array}{l}\text { The use of Canvas enables me to accomplish tasks quicker and more } \\
\text { efficiently. }\end{array}$ \\
\hline PE3 & Using Canvas enhances my effectiveness as a teacher. \\
\hline PE4 & $\begin{array}{l}\text { Through using Canvas, I increase my better chance for receiving good } \\
\text { student feedback. }\end{array}$ \\
\hline \multicolumn{2}{|c|}{ Effort Expectancy } \\
\hline EE1 & I find the interface of Canvas clear and understandable. \\
\hline EE2 & It is easy for me to become skillful at using Canvas. \\
\hline EE3 & I find Canvas easy to use. \\
\hline EE4 & Learning to work with Canvas is easy. \\
\hline \multicolumn{2}{|c|}{ Social Influence } \\
\hline SI1 & My colleagues think that I should use Canvas more innovatively. \\
\hline SI2 & Colleagues, who are important to me, think that I should use Canvas. \\
\hline SI3 & The educational council of my programme supports the use of Canvas. \\
\hline SI4 & In general, the university supports the use of Canvas. \\
\hline SI5 & In general, the faculty supports the use of Canvas. \\
\hline SI6 & $\begin{array}{l}\text { The chairman of my educational council thinks that I should use } \\
\text { Canvas. }\end{array}$ \\
\hline \multicolumn{2}{|c|}{$\begin{array}{l}\text { Facilitating } \\
\text { conditions }\end{array}$} \\
\hline FC1 & I have the resources necessary to use Canvas. \\
\hline $\mathrm{FC} 2$ & Canvas is compatible with the way I teach. \\
\hline FC3 & $\begin{array}{l}\text { A specific person is available for assistance with difficulties when using } \\
\text { Canvas. }\end{array}$ \\
\hline FC4 & I have the knowledge necessary to use Canvas. \\
\hline FC5 & $\begin{array}{l}\text { I feel that I can make informed decisions about which tools/resources } \\
\text { to use within Canvas. }\end{array}$ \\
\hline FC6 & $\begin{array}{l}\text { I feel that I can fully take advantage of Canvas thanks to the resources } \\
\text { within Canvas. }\end{array}$ \\
\hline FC7 & $\begin{array}{l}\text { I have looked for tools outside of Canvas so that I can further innovate } \\
\text { with my teaching through technology. }\end{array}$ \\
\hline \multicolumn{2}{|c|}{ Attitude } \\
\hline ATT1 & The use of Canvas at our university is a good idea. \\
\hline ATT2 & Canvas makes teaching more interesting. \\
\hline АТT3 & Working with Canvas is fun. \\
\hline ATT4 & I enjoy using Canvas. \\
\hline ATT5 & Canvas makes learning more interesting for the students. \\
\hline \multicolumn{2}{|l|}{ Anxiety } \\
\hline ANX1 & I feel apprehensive about using Canvas. \\
\hline
\end{tabular}




\begin{tabular}{|c|c|}
\hline ANX2 & $\begin{array}{l}\text { It scares me to think that I could unintentionally lose information if I } \\
\text { use Canvas. }\end{array}$ \\
\hline ANX3 & $\begin{array}{l}\text { I fear that the information that I post online on Canvas could be } \\
\text { misused. }\end{array}$ \\
\hline ANX4 & $\begin{array}{l}\text { I fear that the information that I post online on Canvas can be } \\
\text { misinterpreted. }\end{array}$ \\
\hline ANX5 & I hesitate to use Canvas for fear of making mistakes I cannot correct. \\
\hline ANX6 & The use of Canvas intimidates me. \\
\hline \multicolumn{2}{|c|}{ Intesity of Use } \\
\hline IU & To what extent do you use Canvas? \\
\hline \multicolumn{2}{|c|}{ Frequency } \\
\hline FREQ & How often do you use Canvas? \\
\hline \multicolumn{2}{|c|}{$\begin{array}{l}\text { Behavioural intention } \\
\text { to innovate }\end{array}$} \\
\hline BII1 & I intend to approach my following course more innovatively. \\
\hline BII2 & $\begin{array}{l}\text { Because of the possibilities that Canvas offers, I plan to approach my } \\
\text { next course more innovatively. }\end{array}$ \\
\hline BII3 & $\begin{array}{l}\text { I predict that I would approach my next course more innovatively, } \\
\text { because of the possibilities offered by Canvas. }\end{array}$ \\
\hline
\end{tabular}




\section{Appendix B: Hierarchical cluster analysis statistics and figures.}

In this appendix all the results are presented from the hierarchical cluster analysis along with the Kmeans cluster analysis of the 4-cluster solution. In Figure B.1, on the scree plot, a noticeable jump can be seen between the fourth and the third last stages, which corresponds to the difference between the 190th and 189th stages in the agglomeration schedule (Table B.1). By examining the dendrogram, a cut-off line at stage 189 reveals four distinct clusters (Figure B.2). Finally, the results of the 4-cluster solution k-means cluster analysis are presented in Table B.2.

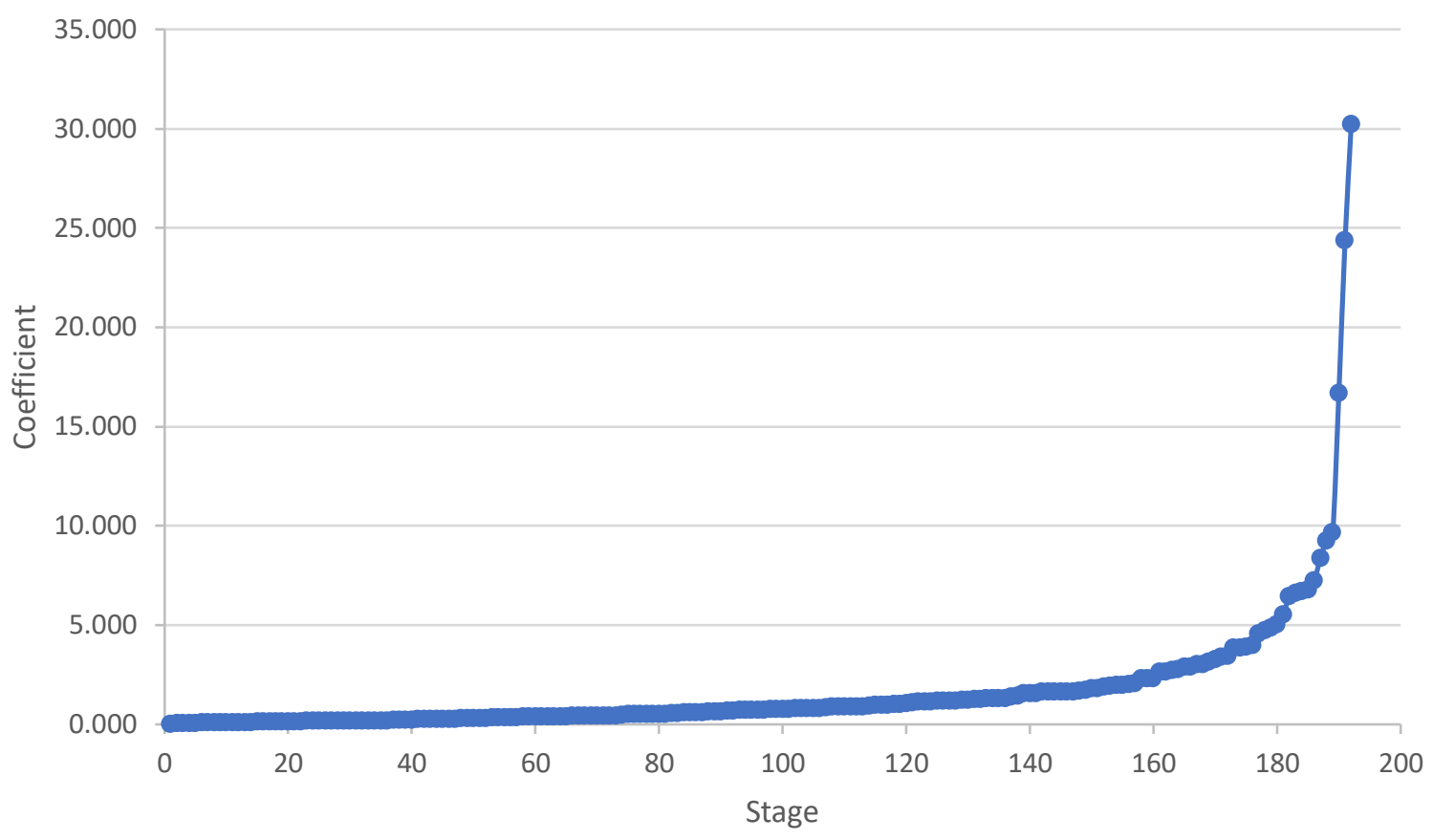

Figure B.1: Scree plot

Table B.1: Agglomeration Schedule (shortened)

\begin{tabular}{lllllll} 
& \multicolumn{3}{c}{ Cluster Combined } & & \multicolumn{3}{c}{ Stage Cluster First Appears } \\
Stage & Cluster 1 & Cluster 2 & Coefficients & Cluster 1 & Cluster 2 & Next Stage \\
\hline 1 & 10 & 52 & .000 & 0 & 0 & 63 \\
2 & 169 & 218 & .028 & 0 & 0 & 22 \\
3 & 138 & 146 & .028 & 0 & 0 & 54 \\
4 & 131 & 194 & .063 & 0 & 0 & 15 \\
. &. &. &. &. &. &. \\
186 & 3 & 19 & 7.216 & 181 & 183 & 188 \\
187 & 1 & 15 & 8.360 & 0 & 176 & 190 \\
188 & 2 & 3 & 9.249 & 184 & 186 & 190 \\
189 & 12 & 49 & 9.664 & 185 & 170 & 192 \\
190 & 1 & 2 & 16.676 & 187 & 188 & 191 \\
191 & 1 & 77 & 24.343 & 190 & 0 & 192 \\
192 & 1 & 12 & 30.219 & 191 & 189 & 0 \\
\hline
\end{tabular}




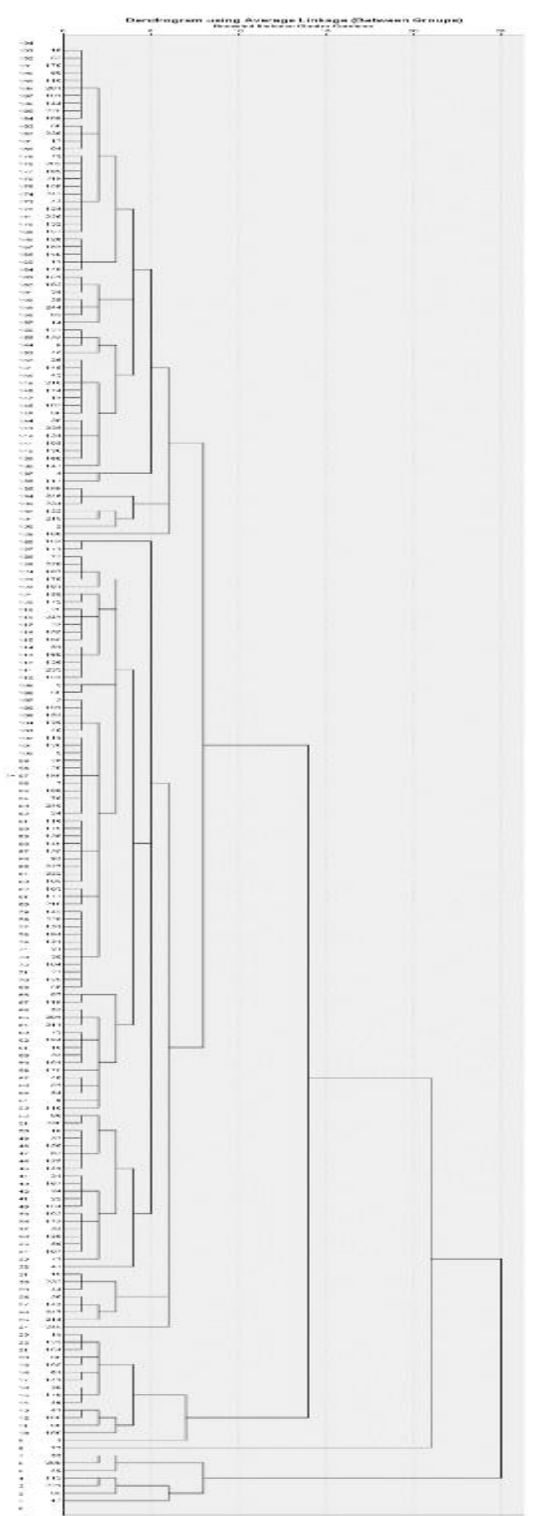

Figure B.2: Dendrogram with 193 cases

Table B.2: Four-cluster solution mean scores with 193 cases (missing $=56$ )

\begin{tabular}{lllll} 
Scales & 1 & 2 & 3 & 4 \\
\hline PE & 5.26 & 2.44 & 3.13 & 4.00 \\
EE & 5.87 & 4.94 & 2.56 & 4.75 \\
FC & 5.37 & 3.43 & 3.17 & 4.07 \\
SIp & 5.30 & 3.26 & 4.12 & 4.77 \\
N in each cluster & 67 & 9 & 27 & 90 \\
\hline
\end{tabular}

